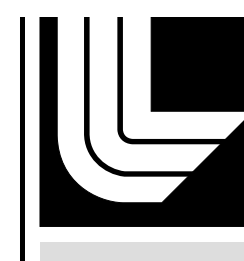

LAW RENCE LIVERMORE N A T IO N A L LABORATORY

\section{Creep of Nearly Lamellar TiAl Alloy Containing W}

A. M. Hodge, L. M. Hsiung, T.G. Nieh

Scripta Materialia

\author{
May 3, 2004
}

\title{
UCRL-JRNL-203926
}

Scripta Materialia 
This document was prepared as an account of work sponsored by an agency of the United States Government. Neither the United States Government nor the University of California nor any of their employees, makes any warranty, express or implied, or assumes any legal liability or responsibility for the accuracy, completeness, or usefulness of any information, apparatus, product, or process disclosed, or represents that its use would not infringe privately owned rights. Reference herein to any specific commercial product, process, or service by trade name, trademark, manufacturer, or otherwise, does not necessarily constitute or imply its endorsement, recommendation, or favoring by the United States Government or the University of California. The views and opinions of authors expressed herein do not necessarily state or reflect those of the United States Government or the University of California, and shall not be used for advertising or product endorsement purposes. 


\title{
CREEP OF NEARLY LAMELLAR TiAI ALLOY CONTAINING W
}

\author{
A.M. Hodge ${ }^{*}$, L.M. Hsiung, T.G. Nieh \\ Materials Science and Technology Division, Lawrence Livermore National Laboratory, \\ 7000 East Avenue, Livermore, CA 94550
}

\begin{abstract}
Effects of $\mathrm{W}$ on the creep resistance of two nearly fully lamellar TiAl alloys with 1.0 and 2.0 at.\%W have been investigated. In the low stress regime (LS) a nearly quadratic $(1.5<\mathrm{n}<2)$ creep behavior was observed. It is found that the addition of $\mathrm{W}$ can improve the creep resistance; however, the addition of excess $\mathrm{W}$ can result in the formation of $\beta$ phase, which produces an adverse effect on the creep strength.
\end{abstract}

Keywords: creep behavior, lamellar TiAl, ultrafine lamellar microstructure, $\beta$ phase

\section{Introduction}

Two-phase $\left[\mathrm{TiAl}\left(\gamma-\mathrm{L} 1_{0}\right)\right.$ and $\left.\mathrm{Ti}_{3} \mathrm{Al}\left(\alpha_{2}-\mathrm{DO}_{19}\right)\right]$ nanoscale nearly lamellar TiAlbased alloys have potential as high-temperature components in turbine and combustion engines as they have good creep performance and oxidation resistance [1,2]. However, the balance between the tensile behavior of duplex structures and the creep strength of nearly and fully lamellar structures is a work in progress. It has been suggested that further microstructure refinement will lead to a better performing alloy by improving both room temperature toughness and elevated temperature creep resistance [2-4].

Improvements in the room temperature and high temperature behavior of duplex, nearly lamellar and fully lamellar TiAl-based alloys have been made by additions of multiple elements such as $\mathrm{Si}, \mathrm{Cr}, \mathrm{Nb}$, and $\mathrm{B}$, which have shown great potential in *Corresponding author e-mail : hodge4@1lnl.gov 
controlling and stabilizing the microstructure. For example, $\mathrm{W}$ additions stabilize the $\alpha_{2}$ phase [5] and improve creep resistance [6], while B additions affect the initial lamellar spacing [7]. Other elements, such as $\mathrm{Nb}$, improve oxidation resistance as well as creep properties $[8,9]$.

Currently, most research on creep of highly engineered duplex and lamellar structures (containing more than five elements), with few exceptions [10], has focused on alloys containing $\mathrm{Cr}$, since it was believed that $\mathrm{Cr}$ would increase room temperature ductility; however, since $\mathrm{Cr}$ is a $\beta$ phase stabilizer and reduces the creep resistance, options to exclude Cr have sparked interest [11, 12].

It was previously suggested that additions of $\mathrm{W}$ could impede interface sliding and thus improve the overall creep resistance of TiAl $[13,14]$. However, $\mathrm{W}$ is also a beta stabilizer and it is known that the presence of beta phase can weaken the creep strength of TiAl $[4,12]$. Thus, excessive amount of $\mathrm{W}$ is expected to produce adverse effects on the creep resistance.

This study presents a comparison of the creep behavior on the low stress regime of two finely tuned, nearly lamellar microstructures containing relatively high amounts of W (1.0 and 2.0 at.\%). Previous publications by Liu et al. [11], Kim and Hong [15] and Zhou et. al [16] presented studies on the microstructure with compositions of similar alloys with 0.5 to 2.0 at.\%W but included no creep studies.

\section{Experimental Procedures}

Cast materials with compositions Ti-46.5Al-3.0Nb-2.0W-0.10B and Ti-46.5Al3.0Nb-1.0W-0.10B (at.\%), were hot-extruded near the alpha-transus temperature $\left(1345^{\circ} \mathrm{C}\right)$ 
at Oak Ridge National Laboratory. Detailed procedures have been described elsewhere [11]. The materials are, herein, denoted as $1 \mathrm{~W}$ and $2 \mathrm{~W}$ alloys. The as-extruded samples were additionally heat treated in air at $900^{\circ} \mathrm{C}$ for 2 hours before creep testing to relieve residual stresses. Tensile samples were cut by electrical discharge machining (EDM) with a gauge dimension of $20.0 \times 3.0 \times 2.0 \mathrm{~mm}$.

Creep tests were performed in air on a dead-load creep tester with a lever arm ratio of 16:1 (Satec Systems, Groove City, Pa). A linear voltage displacement transducer (which was calibrated before each experiment) was attached to the lower end of the longitudinal extensometer to measure the relative displacement of the sample. The furnace was brought to within $\pm 2.5^{\circ} \mathrm{C}$ of the test temperature and equilibrated for over 1 hour before applying load. The test temperature spanned a range from 650 to $815^{\circ} \mathrm{C}$. At a given temperature, a series of incremental loads were applied to a test specimen, yielding up to 3 strain rate measurements, with no more than 5\% total strain accumulated in the specimen. Loads ranged from 50 to $500 \mathrm{MPa}$.

Grain size measurements and microstructure studies were performed using optical microscopy, scanning electron microscope (SEM) and transmission electron microscope (TEM). Samples for optical metallography were etched using a solution of $98.5 \mathrm{ml} \mathrm{H}_{2} \mathrm{O}$, $1 \mathrm{ml} \mathrm{HNO}$ and $0.5 \mathrm{ml} \mathrm{HF}$. TEM samples were prepared by a twin-jet electropolishing technique.

\section{Results and discussion}

The overall microstructures for the etched $1 \mathrm{~W}$ and $2 \mathrm{~W}$ alloys are presented in Figures $1 \mathrm{a}$ and $1 \mathrm{~b}$. The lamellar grains are in the range $15-50 \mu \mathrm{m}$ and make up $\approx 80 \%$ 
vol. fraction. This type of large lamellar volume in a Ti-46.5At $2 \mathrm{Cr} 2 \mathrm{Nb}$ alloy has been shown to improve the overall fracture toughness when compared to structures with less than $80 \%$ volume of lamellar grains [3].

The typical microstructure of the $2 \mathrm{~W}$ alloy observed by TEM is shown in Figure 2. The microstructure mainly consists of $\gamma / \alpha_{2}$ lamellar colonies (the width of $\gamma$ lamellae varies between 100 and $200 \mathrm{~nm}$, and the width of $\alpha_{2}$ lamellae varies between $10 \mathrm{~nm}$ and $50 \mathrm{~nm}$ ) associated with somesingle -phase $\gamma$ grains located at colony boundaries. The widths of $\alpha_{2}$ and $\gamma$ lamellae within the lamellar colonies are considered to be ultrafine compared with those in lamellar TiAl alloys fabricated by conventional processing techniques $[17,18]$.

Close examination of the microstructure in Figure 3 shown in the longitudinal direction reveals that the $2 \mathrm{~W}$ alloy actually consists of an appreciable amount of $\beta$ phase, which has an elongated needle like shape. Note that the lamellar grains are not elongated; only the beta phase is elongated, since it is softer. In contrast, no $\beta$ phase was observed in the $1 \mathrm{~W}$ alloy. This result is consistent with previous microstructural studies by Yin et al. [19] on a Ti-47At (1.5-2.1)W-0.5Si (at.\%) alloy in which small increments of $\mathrm{W}$ increase the amount of $\beta$ phase, i.e., at $1.5 \mathrm{~W}$ there was only small amount of $\beta$ phase, while at $2.1 \mathrm{~W}$ there was a significant amount of $\beta$ phase in the form of block, rodlike and needle-like shapes.

Creep curves (i.e. strain versus time curves) at $760^{\circ} \mathrm{C}$ and at an applied stress of $208 \mathrm{MPa}$ for both alloys are shown in Figure 4. The 1W alloy is apparently stronger than the $2 \mathrm{~W}$ alloy. Note that the primary creep is within previously reported values for nearly fully lamellar systems $[4,8,9,12,20,21]$. It is also noted that when strain rate 
versus strain is plotted at different stresses, the tests showed a behavior more typical of fully lamellar structures, i.e., there was not a pronounced dip followed by an increase in the strain rate, as shown by Oikawa and Maruyama [22]. Rather, after a minimum strain rate is reached, it remains "steady", suggesting that the overall microstructure is stable.

To compare the overall creep behavior, the relationship between strain rate and stress $(\sigma)$ is established using the power-law equation:

$$
\dot{\varepsilon}_{\min }=A \cdot \sigma^{n} \exp \left(\frac{-Q}{R T}\right)
$$

where $\mathrm{A}$ is a constant, $\mathrm{n}$ is the stress exponent, $\mathrm{Q}$ is the activation energy, $\mathrm{R}$ is the gas constant and $\mathrm{T}$ is the absolute temperature.

The double logarithm of the minimum strain rate versus stress for both alloys at $760^{\circ} \mathrm{C}$ is plotted in Figure 5. Note that at LS, there is a creep exponent (n) of 1.8 and 1.7 for the $1.0 \mathrm{~W}$ and $2.0 \mathrm{~W}$ respectively, which indicates a transition region of diffusional creep showing a nearly quadratic creep exponent. These values suggest that the mechanisms in the two alloys are similar and the presence of beta phase weakens the $2 \mathrm{~W}$ alloy, thus causing a downward shift in the curve.

It is worth noting that several creep studies have been performed with alloys consisting of over 1 at.\% $\mathrm{W}$, such as Ti-46At 2W-0.5Si and other ABB type alloys [23], fully lamellar Ti-48At 2W [14] and nearly lamellar (CTI-8) Ti-47At (2-4)Nb-(0.51.0)W-(0.08-0.18)B[10]. These samples were crept at $760^{\circ} \mathrm{C}$ and did not show a clear effect on the creep behavior because of a low W content. It has been suggested by Yu et al. $[24,25]$ that when a critical $\mathrm{W}$ solubility in $\operatorname{TiAl}(\gamma)$ and $\operatorname{Ti}_{3} \mathrm{Al}\left(\alpha_{2}\right)$ is reached the $\beta$ phase becomes more stable and precipitates into $\beta$ particles. According to previous studies [19], the critical solubility value at which there is formation of $\beta$ precipitates 
seems to be around 1.0 to $1.5 \mathrm{~W}$. At values of $1.5 \mathrm{~W}$ or less, $\mathrm{W}$ does improve the creep resistance by acting as a pinning point for interfacial dislocations; however, excessive $\mathrm{W}$ leads to the formation of $\beta$ precipitates, which produces a detrimental effect (since the $\beta$ phase is softer than $\gamma$ and $\alpha_{2}$ phases) on the creep strength [12]. It should also be note that $\mathrm{Nb}$ is also a $\beta$ stabilizer [26], however, since the amount of $\mathrm{Nb}$ is identical in both the $1 \mathrm{~W}$ and $2 \mathrm{~W}$ alloys the occurrence of the $\beta$ phase in this case is solely associated with the W content.

In the LS regime, values of the creep exponent of near quadratic behavior have been observed in nearly and fully lamellar alloys $[12,27]$, which are comparable to the present study reported here. This near quadratic creep behavior in the LS regime is due to interface sliding mechanisms as proposed by Hsiung and Nieh [20]; at higher stresses, the lattice dislocations are activated and become dominant, thus changing the deformation mechanism. At the high stress regime (above $300 \mathrm{MPa}$ ), there is a change in slope to power law creep, demonstrating a change in mechanisms from diffusional/glide to power law breakdown $(n>5)$ and showing creep exponents greater than 5 for both alloys. This is consistent with previously reported trends in similar alloys with duplex, nearly lamellar or fully lamellar TiAl based alloys [13, 21, 28, 29].

To further elucidate on the creep mechanism in the LS regime, additional tests at various temperatures were conducted, as shown in Figure 6a. These data were used to obtain the activation energy in the LS regime for the 2.0 at. $\% \mathrm{~W}$ alloy. The value of the activation energy was found to be $145.2 \mathrm{~kJ} / \mathrm{mole}$ as shown in Figure $6 \mathrm{~b}$. This value is noted to be similar to those found elsewhere for nearly lamellar and fully lamellar alloys containing $\mathrm{Cr}$. It is close to that of the activation energy for boundary diffusion $[20,21$, 
28], thus further validating the notion of the interface sliding mechanism being dominant in this regime.

It has been shown that fully lamellar structures have better creep resistance than nearly lamellar alloys, but by comparing the alloys in this study to other alloys with similar lamellar spacing, the overall minimum strain rate in the LS regime is comparable to fully lamellar systems $[21,28]$. This indicates that $\mathrm{W}$ does improve the creep behavior. However, when an alloy has an over 1.0 at.\% $\mathrm{W}$ the overall creep performance degrades due to the presence of $\beta$ stringers. Overall, the creep behavior of both alloys was as good as those of nearly lamellar alloys for similar structures.

\section{Conclusions}

The nearly lamellar TiAl alloys with 1.0 and 2.0 at.\%W performed comparably to fully lamellar alloys of similar compositions processed by powder metallurgy [13, 21, 28, 29]. The 1.0 at. $\% \mathrm{~W}$ alloy performed better than the 2.0 at. $\% \mathrm{~W}$. Microstructural examination showed the presence of soft $\beta$ phase in the 2 at. $\% \mathrm{~W}$-alloy. Note that the creep mechanism of these alloys in the low stress regime is believed to be dominated by interface sliding, as suggested by a nearly quadratic creep exponent for both alloys and an activation of energy of $145.2 \mathrm{~kJ} / \mathrm{mole}$ for the 2.0 at. $\% \mathrm{~W}$.

The addition of $\mathrm{W}$ does seem to improve the overall creep performance of the nearly lamellar alloys. However, the excessive addition of $\mathrm{W}$ causes a degradation of creep strength because of the presence of soft $\beta$ phase. 


\section{Acknowledgements}

This work was performed under the auspices of the US Department of Energy by the University of California, Lawrence Livermore National Laboratory under contract no. W7405-Eng-48. Dr. C.T. Liu at Oak Ridge National Laboratory is gratefully acknowledged for providing the TiAl alloys and Ms. G.G. Gaustad is acknowledged for her assistance on preliminary tests. 


\section{References}

1. $\quad$ Brady, M.P., et al. JOM, 1996. 48(11): p. 46.

2. Appel, F. and R. Wagner. Mater Sci Eng, 1998. R22(5): p. 187.

3. Guo, F.A., et al. Acta Mater, 2003. 51: p. 5349.

4. Seo, D.Y., J. Beddoes, and L. Zhao. Metall Mater Trans, 2003. 34A: p. 2177.

5. Larson, D.J., C.T. Liu, and M.K. Miller. Intermetallics, 1997. 5: p. 497.

6. Martin, P.L., M.G. Mendiratta, and H.A. Lipsitt. Metall Mater Trans, 1983. 14A: p. 2170.

7. Zhang, W.J. and S.C. Deevi. Mater Sci Eng, 2002. 337A: p. 17.

8. Zhang, W.J., et al. Mater Sci Eng, 2001. 315A: p. 250.

9. Appel, F., et al. Metall Mater Trans, 2003. 34A: p. 2149.

10. Zhang, W.J. and S.C. Deevi. Intermetallics, 2002. 10: p. 603.

11. Liu, C.T., J.L. Wright, and S.C. Deevi. Mater Sci Eng, 2002. 329-331A: p. 416.

12. Wang, J.G. and T.G. Nieh. Intermetallics, 2000. 8: p. 737.

13. Hsiung, L.M. and T.G. Nieh. Mater Sci Eng, 2004. 364A: p. 1.

14. Beddoes, J., et al., Effect of composition and lamellar microstructure on creep properties of P/M near $\gamma$-TiAl alloys, in Gamma Titanium Aluminides, Y.W. Kim, R. Wagner, and M. Yamaguchi, Editors. 1995, Warrendale (USA). p. 959.

15. Kim, H.Y. and S.H. Hong. Mater Sci Eng, 1999. 271A: p. 382.

16. Zhou, L.Z., V. Lupinc, and J.T. Guo. Mater Sci Eng, 2003. 354A: p. 97.

17. Schillinger, W., et al. Intermetallics, 2002. 10: p. 459.

18. Wang, J.G., L.M. Hsiung, and T.G. Nieh. Intermetallics, 1999. 7: p. 757.

19. Yin, W.M., V. Lupinc, and L. Battezzati. Mater Sci Eng, 1997. 239-240A: p. 713.

20. Hsiung, L.M. and T.G. Nieh. Intermetallics, 1999. 7: p. 821.

21. Wang, J.N., et al. Acta Mater, 2002. 50: p. 1307.

22. Oikawa, H. and K. Maruyama, creep behavior of single-phase and two-phase TiAl binary alloys, in Gamma Titanium Alumindes Y. -W. Kim, R. Wagner, and M. Yamaguchi, Editors. 1995, TMS. p. 919.

23. Larsen, D.E. Mater Sci Eng, 1996. 213A: p. 128.

24. Yu, R., et al. Intermetallics, 2002. 10: p. 661.

25. Yu, R., L.L. He, and H.Q. Ye. Phys Rev B, 2002. 65.

26. Liu, Z.C., et al. Intermetallics, 2002. 10(7): p. 653.

27. Hsiung, L.M., et al. Mater Sci Eng, 2002. 329-331A: p. 637.

28. Wang, J.N. and T.G. Nieh. Acta Mater, 1998. 46(6): p. 1887.

29. Worth, B.D., J.W. Jones, and J.E. Allison. Metall Mater Trans, 1995. 26A: p. 2947. 

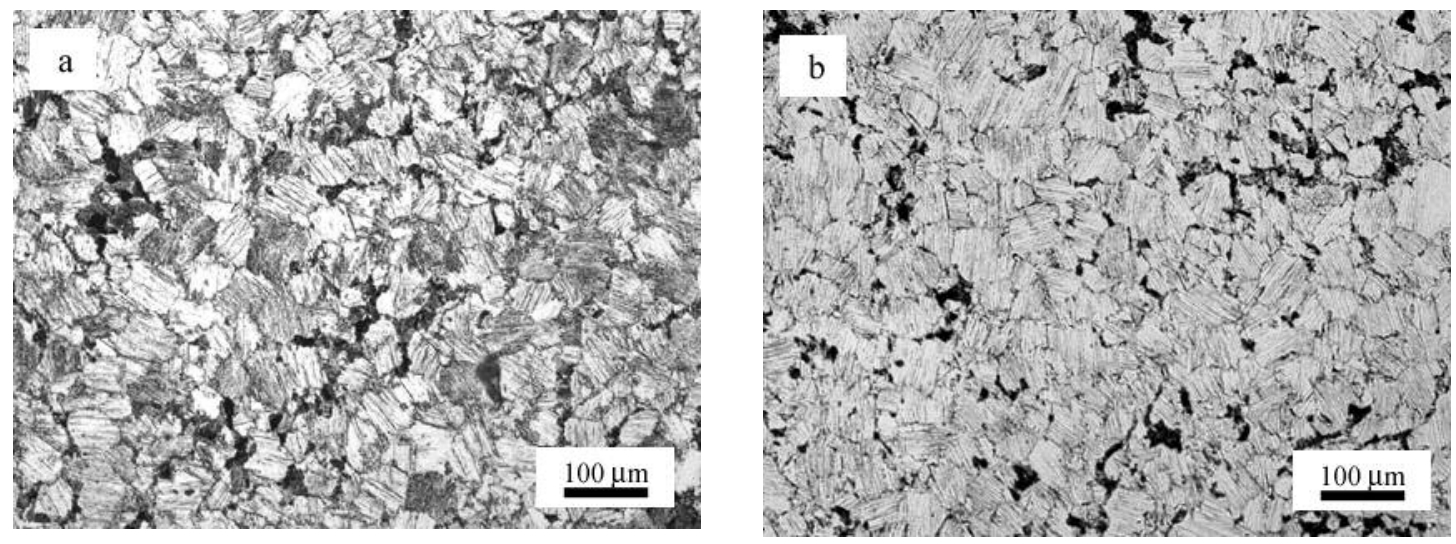

Figure 1. Cross-sectional optical micrographs of etched TiAl alloys: (a) $1.0 \mathrm{~W}$ and b) $2.0 \mathrm{~W}$

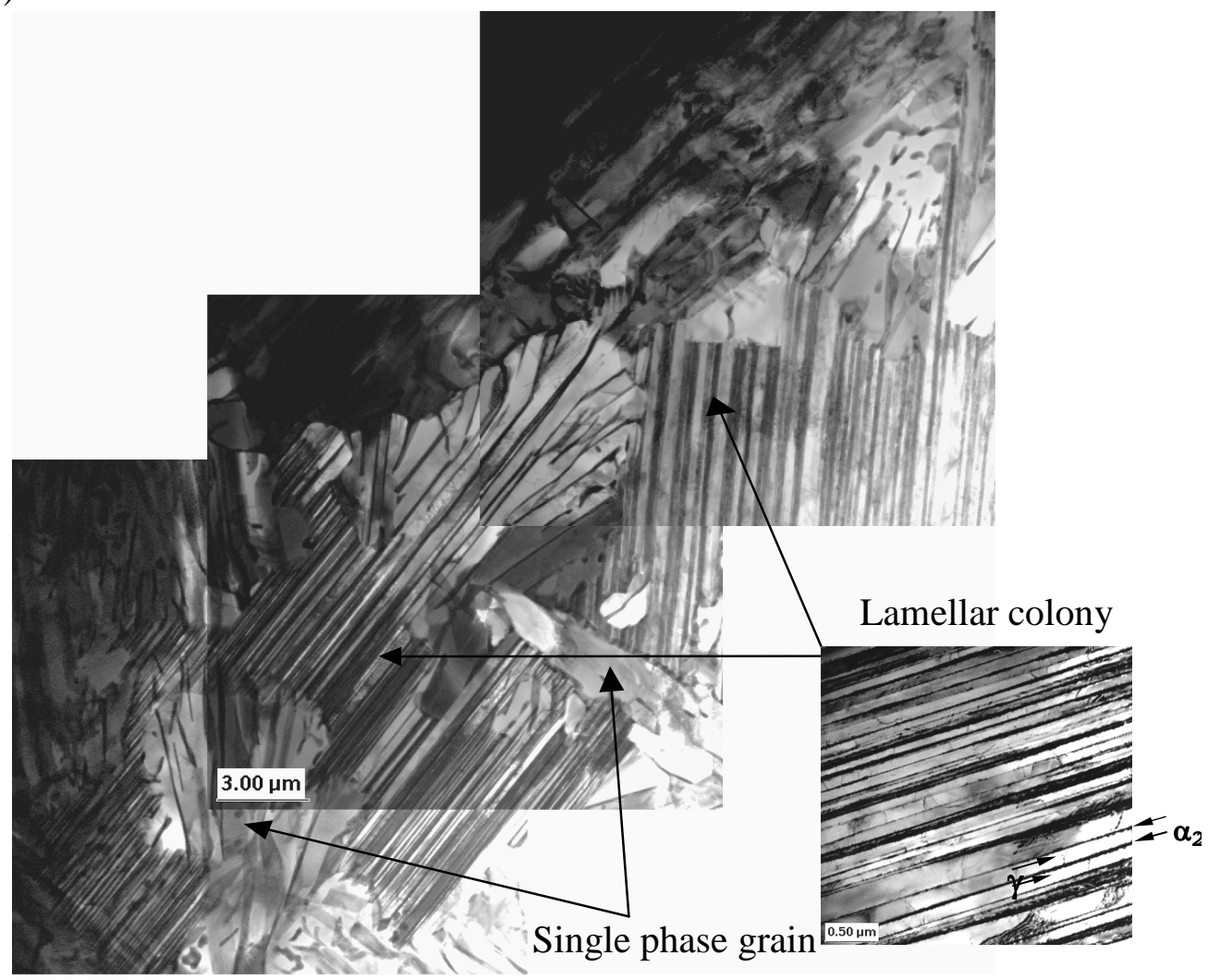

Figure 2. TEM micrograph of the $2 \mathrm{~W}$ sample before creep test noting the typical lamellar structure 


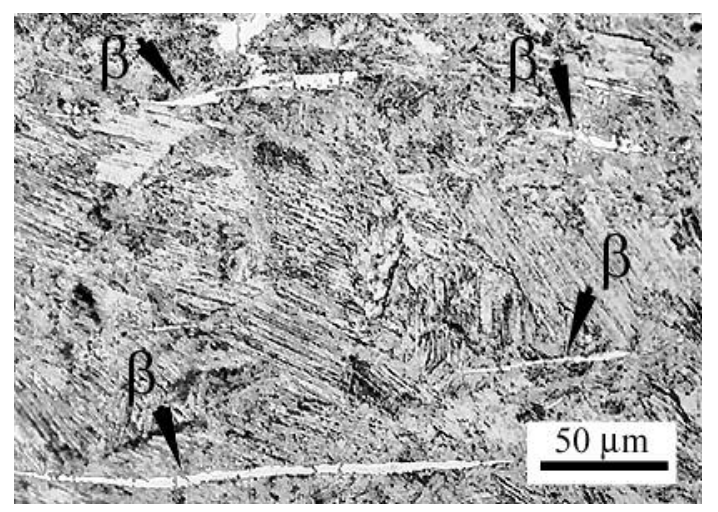

Figure 3. Optical micrograph of 2.0W alloy observed parallel to the extrusion direction

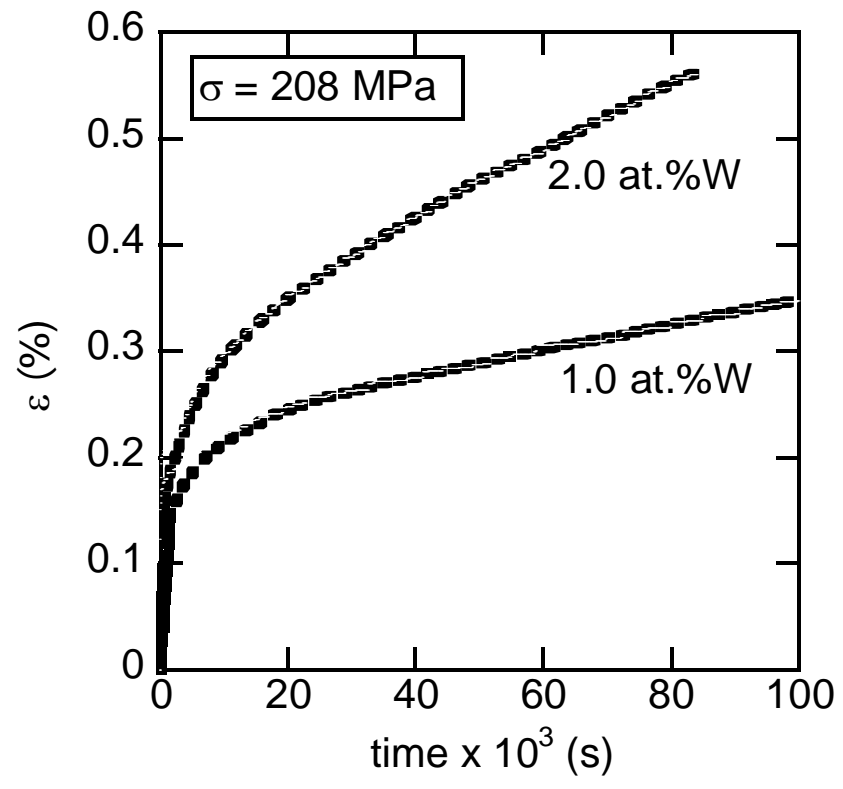

Figure 4. Stress vs. time curves for 1.0 and 2.0 at. $\% \mathrm{~W}$ alloys at $\sigma=208 \mathrm{MPa}$ and $\mathrm{T}=760 \mathrm{oC}$. 


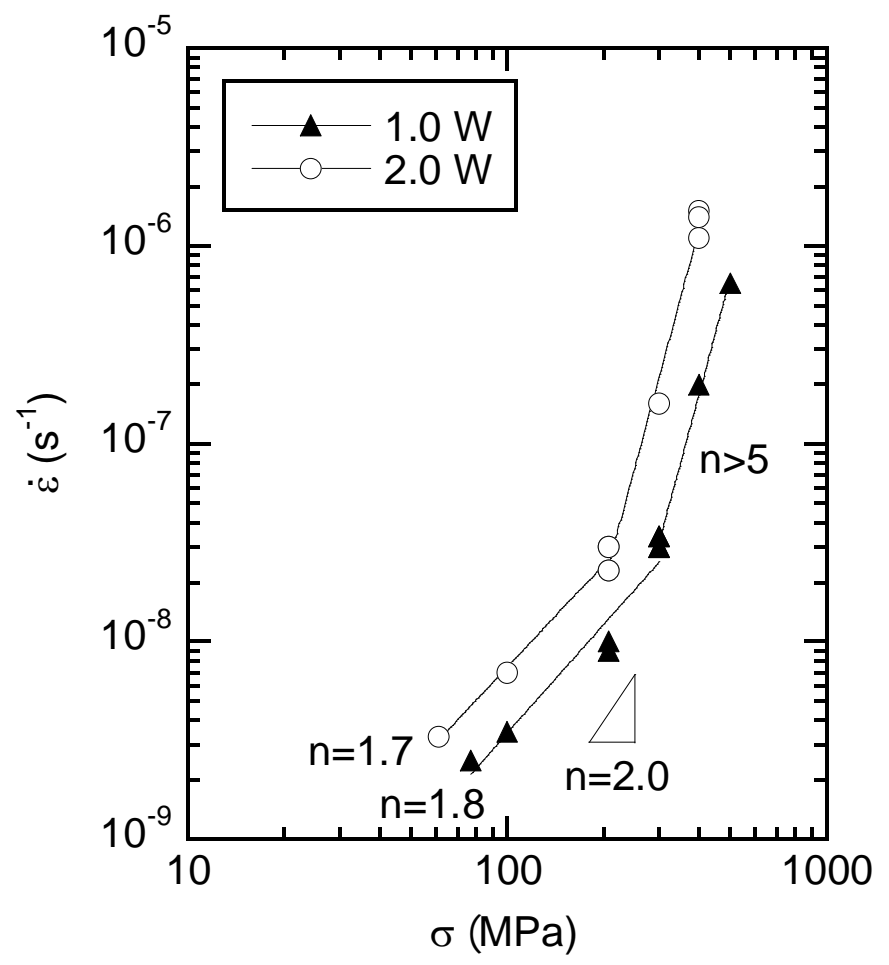

Figure 5. Strain rate vs. stress curves for 1.0 and 2.0 at. $\% \mathrm{~W}$ alloys at $7600 \mathrm{C}$. 

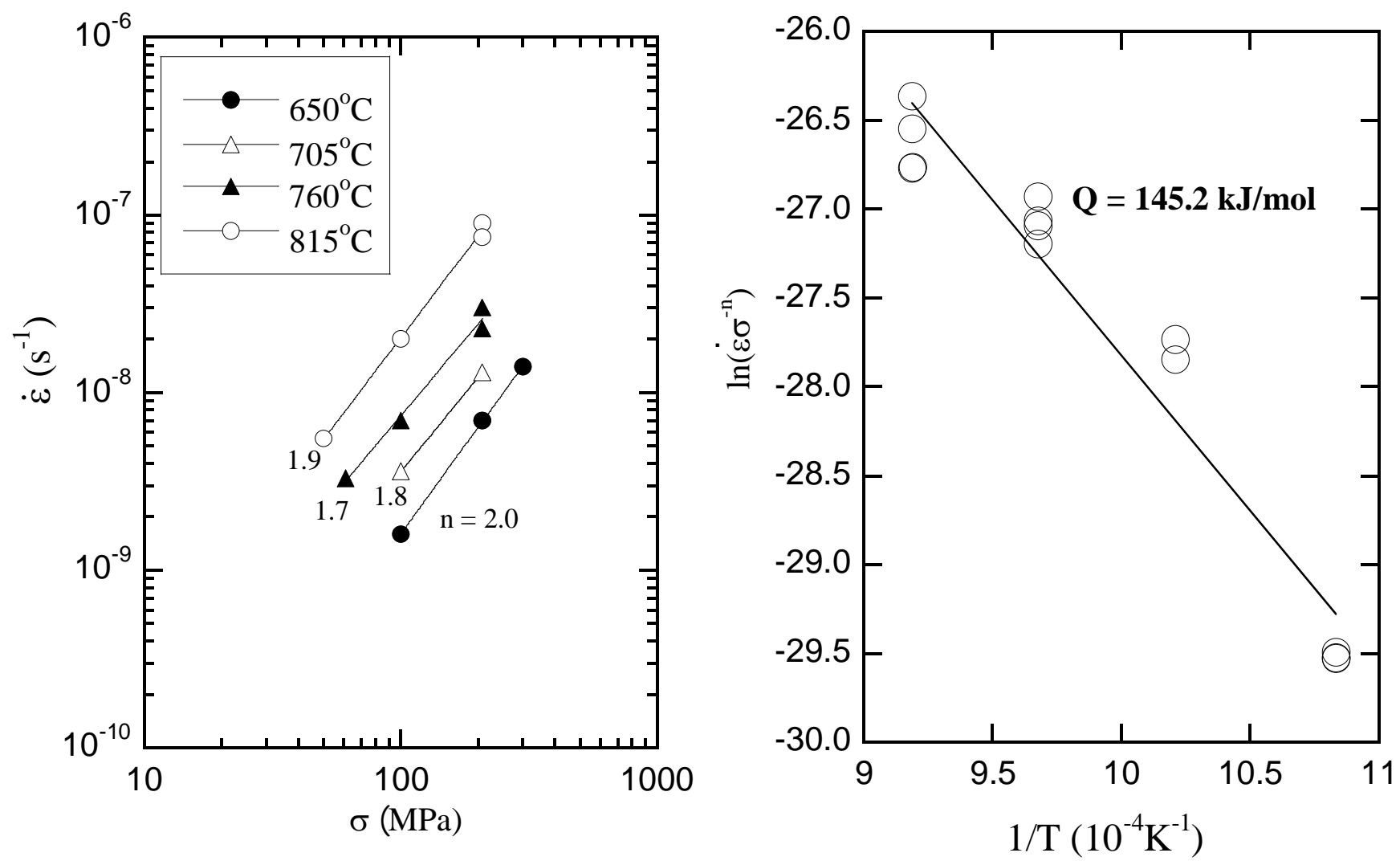

Figure 6a. Strain rate vs. stress curve at the $\mathrm{LS}$ regime for 2.0 at. $\% \mathrm{~W}$ between $650 \mathrm{oC}$ to $8150 \mathrm{C}$

Figure $6 \mathrm{~b}$. Strain rate vs. the inverse of absolute temperature at the LS regime for 2.0 at.\%W alloy 
